\title{
Perinatal risk factors for major intraventricular haemorrhage in the Australian and New Zealand Neonatal Network, 1995-97
}

\author{
A M Heuchan, N Evans, D J Henderson Smart, J M Simpson, on behalf of the \\ Australian and New Zealand Neonatal Network
}

See end of article for authors' affiliations

\section{Correspondence to:} Dr N Evans, Department of Neonatal Medicine, Royal Prince Alfred Hospital,

Camperdown, Sydney, NSW 2050 Australia: nevans@med.usyd.edu.au

Accepted for publication 13 November 2001

\begin{abstract}
Background: In 1995, large differences were identified in rates of grade 3-4 intraventricular/ periventricular haemorrhage (major IVH) among neonatal intensive care units (NICUs) in the Australian and New Zealand Neonatal Network.

Aims: To develop a predictive model for major IVH in order to allow risk adjustment for the variation in rates of major IVH among NICUs.

Methods: Rates of IVH were determined in 5712 infants of 24-30 weeks gestation born from 1995 to 1997. Significant antenatal and perinatal variables for major IVH in 1995 and 1996 were identified by univariate and multivariate analysis. A predictive model was developed and then validated on 1997 data.

Results: Rates of all grades of IVH fell from 1995 to 1997 (30.4 to 24.3\%) but wide interunit variation remained. Seven antenatal and perinatal characteristics had significant association with major IVH: fetal distress, intrauterine growth restriction (protective), antenatal corticosteroids (protective), gestational age, 1 minute Apgar <4, male gender, and transfer after birth. A predictive model based on the last five of these variables was developed using data from 1995 and 1996 which gave an area under the receiver operator characteristic (ROC) curve of 0.76 . This model was then validated on the 1997 dataset where an identical ROC curve resulted.

Conclusions: Antenatal and perinatal factors are important in the pathogenesis of major IVH. The predictive model developed from these factors can be used to adjust for confounders in interunit outcome comparison.
\end{abstract}

$\mathrm{T}$ he Australian and New Zealand Neonatal Network (ANZNN) consists of all 29 level III neonatal intensive care units (NICUs) in Australia and New Zealand. A dataset of 60 variables is collected by each unit, using agreed definitions, on all infants born before 32 weeks gestation or with a birth weight less than $1500 \mathrm{~g}$, and all babies needing major surgery or requiring assisted ventilation for over four hours. Data collection started at the beginning of 1995.

In the 1995 data collection, wide variation in rates of major (grades 3 and 4) IVH among NICUs became apparent, with a range from less than $5 \%$ to $20 \%$. This study was established to examine factors responsible for these differences in outcomes. When comparing outcomes among different NICUs, ${ }^{1}$ the importance of adjusting for case mix and potential bias from natural variance has been emphasised in the literature. ${ }^{2}$ The large dataset of the ANZNN provided us with a unique opportunity to develop a predictive model for major IVH and apply it to make meaningful risk adjusted comparisons among NICUs.

\section{SUBJECTS AND METHODS}

The cohort of infants used in this analysis was selected from the pooled data of 1995 to 1997 . Infants of gestational age $<24$ weeks $(\mathrm{n}=127)$ were excluded, as not all NICUs routinely resuscitated these infants. Infants born after 30 weeks were also excluded ( $\mathrm{n}=1704)$, as the incidence of grade $3-4 \mathrm{IVH}$ (major IVH) in this population was very low (1.7\%). Infants who died on day $1(n=130)$ were excluded because cranial ultrasound reports were not available, as were other cases without cranial ultrasound reports $(n=570)$, unless there were postmortem data $(n=23)$. The mean proportion of missing scans was $4.4 \%$, with all except one unit having less than $8 \%$ missing data; that unit had a missing data rate of $14.9 \%$. A retrospective validation relating cranial ultrasound reports to postmortem findings was undertaken; two of 30 cases showed a discrepancy in grading. Cases from one unit were excluded because of incomplete data collection and the cases of four units attached to children's hospitals were also excluded as their cases represented a different population. This left 5712 babies included in the analysis.

All units used the ANZNN definitions for cranial ultrasound reporting based on the Papile gradings. ${ }^{3}$ Routine cranial ultrasound screening of all infants $<32$ weeks gestation during the first 10 days of life was reported by all NICUs in 1995. Reports were primarily by trained radiologists, but in some units clinicians had input into the final report.

Retrospective analysis of the above cohort of 5712 babies was undertaken in several stages using standard statistical software (SPSS version 9). Initially, trends in overall incidence and interunit variation in rates of major IVH from 1995 to 1997 were examined. Univariate analysis of all variables collected in 1995 and 1996 up to and including the 1 minute Apgar score was then undertaken to detect potential risk and protective factors. The focus was on antenatal and perinatal variables as the origin of IVH is in early neonatal life. ${ }^{4-6}$

Abbreviations: ANZNN, Australian and New Zealand Neonatal Network; IUGR, intrauterine growth restriction; IVH, intraventricular haemorrhage; NICU, neonatal intensive care unit; $\mathrm{PIH}$, pregnancy induced hypertension; PROM, prolonged rupture of membranes; ROC, receiver operator characteristic 


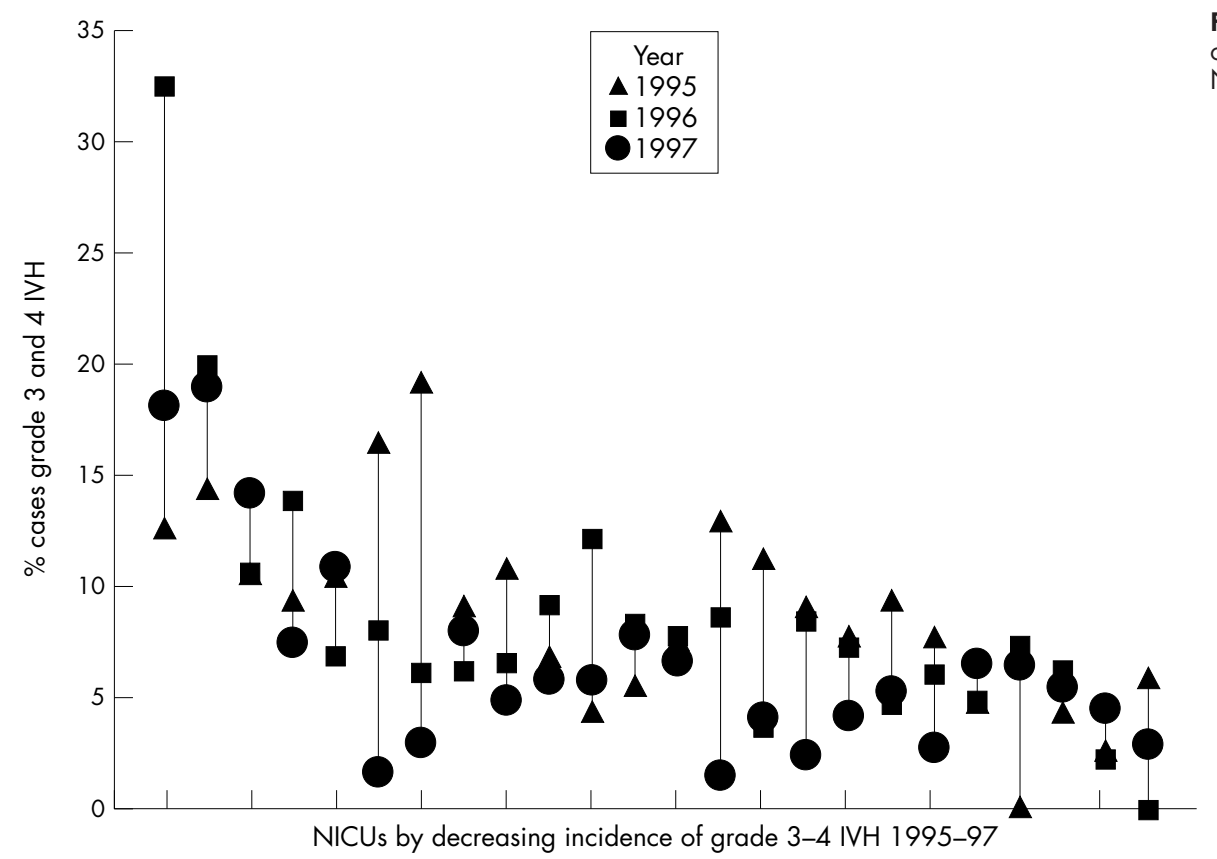

Figure 1 Variation in annual rates of major IVH between and within NICUs from 1995 to 1997.

The dichotomous outcome variable of no major IVH (grade 0-2 IVH) or major IVH (grade 3-4 IVH) was used in this analysis. Any variable with $\mathrm{p}<0.05$ on univariate analysis and any other factors thought to have a role in the pathogenesis of IVH were then entered into a multivariate logistic regression model. Variables were entered in antenatal and then perinatal epochs and removed from the model if they were not significant at $p<0.01$. To aid in identification of any confounding variables, only the least significant term was removed at each stage. This process identified those factors that remained significant after simultaneous adjustment for all other risk/protective factors in the 1995 and 1996 cohorts. These factors were used to formulate a predictive model for the development of major IVH; the predicted probability $(\mathrm{P})$ of each case developing major IVH was calculated using equations 1 and 2:

$$
\begin{aligned}
& Y=\ln [P /(1-P)]=\alpha+\beta_{1} x_{1}+\beta_{2} x_{2}++\beta_{k} x_{k} \\
& P=\exp (Y) /[1-\exp (Y)]
\end{aligned}
$$

where $x_{i}$ represents one of the predictor variables and $\beta_{\mathrm{i}}$ its regression coefficient in the logistic regression model.

The discriminatory properties of this model were assessed by measuring the area under the receiver operator characteristic (ROC) curve. The model derived from the 3772 babies in the 1995/96 dataset was then validated on the 1940 babies in the 1997 dataset. The ability of the model to predict grade 2-4 $\mathrm{IVH}$, mortality, and periventricular leucomalacia were also assessed using ROC curve techniques.

\section{RESULTS}

\section{Overall rates of IVH}

The mean gestation of the 5712 babies in the whole 1995-97 cohort was 27.8 weeks (range 24-30 weeks) and the mean birth weight was $1104 \mathrm{~g}$ (range 332-2650 g). Those excluded because of lack of cranial ultrasound reports had a mean gestation of 27.9 weeks and mean birth weight of $1175 \mathrm{~g}$. The incidence of all IVH decreased from $30.4 \%$ in 1995 to $24.0 \%$ and $24.3 \%$ in 1996 and 1997, respectively. The incidence of grade 3-4 IVH (major IVH) fell from $7.5 \%$ to $5.9 \%$ over this time period. The median incidence of major IVH across the NICUs decreased from $9.0 \%$ (interquartile range (IQR)
$4.0-14.0 \%$ ) in 1995 to $7.3 \%$ (IQR $5.7-10.9 \%$ ) in 1996 and $5.8 \%$ (IQR 3.6-7.8\%) in 1997. While the overall rates fell the wide interunit variation remained (fig 1 ).

\section{Antenatal variables}

Table 1 shows the characteristics of the nine antenatal variables explored and their relation with the development of major IVH. Intrauterine growth retardation (as defined from antenatal parameters) was protective against IVH. The strongest protective association was the administration of antenatal corticosteroids. The frequency of administration was high and rose from $79.0 \%$ to $86.0 \%$ over the three year period. The protective effect was greatest (odds ratio $0.4,95 \%$ CI 0.3 to 0.5 ) if the course was "complete" (more than one dose administered and the first dose $>24$ hours prior to delivery), but was also significant if administration of the first dose was $<24$ hours prior to delivery (OR $0.7,95 \%$ CI 0.5 to 0.9 ). Therefore partial and complete antenatal corticosteroids were entered as separate categories in our multivariate logistic regression analysis.

\section{Perinatal variables}

Table 2 shows the characteristics of the perinatal variables explored and their association with the development of major IVH. Gestation was the dominant risk factor, with risk increasing as gestation decreased from 30 to 24 weeks. Birth weight was not selected for inclusion in our model as accurate gestational age data is available for most pregnancies in Australia and New Zealand and is the best marker of maturity. There was no significant relation between birth weight centile and major IVH. We did not include 5 minute Apgar score or intubation at delivery as variables, as they may be more indicative of resuscitation skills than condition at birth.

\section{Multivariate logistic regression analysis and model development}

Seven variables remained significant $(\mathrm{p}<0.01)$ in the multivariate analysis: gestational age, transfer after birth, any antenatal corticosteroids, 1 minute Apgar $<4$, male gender, fetal distress, and intrauterine growth restriction (IUGR) (table 2). The variables excluded were prolonged rupture of membranes (PROM), pregnancy induced hypertension (PIH), antepartum haemorrhage, and mode of delivery. Mode of delivery became non-significant when considered simultaneously with either 
Table 1 Univariate analysis of antenatal risk factors for grades 3-4 IVH in 5712 infants, 1995-97

\begin{tabular}{|c|c|c|c|c|}
\hline \multirow[b]{2}{*}{ Prenatal characteristic } & \multirow{2}{*}{$\begin{array}{l}\text { Yes } \\
\text { Number (\%) with major } \\
\text { IVH }\end{array}$} & \multicolumn{2}{|l|}{ No } & \multirow[b]{2}{*}{ Unadjusted OR (95\% CI) } \\
\hline & & $\begin{array}{l}\text { Number (\%) with major } \\
\text { IVH }\end{array}$ & Missing data (n) & \\
\hline Transfer after birth & $78 / 597(13.1 \%)$ & $306 / 5014(6.1 \%)$ & 101 & 2.31 (1.77 to 3.01$)$ \\
\hline Prolonged rupture of membranes & $60 / 1198(5.0 \%)$ & $329 / 4393$ (7.5\%) & 121 & $0.66(0.49$ to 0.87$)$ \\
\hline Preterm labour & $263 / 3280(8.0 \%)$ & $131 / 2389(5.5 \%)$ & 43 & 1.51 (1.21 to 1.87$)$ \\
\hline Pregnancy induced hypertension & $41 / 1036(4.0 \%)$ & $347 / 4568(7.6 \%)$ & 108 & $0.50(0.36$ to 0.70$)$ \\
\hline Antepartum haemorrhage & $107 / 1308(8.2 \%)$ & $282 / 4296(6.6 \%)$ & 108 & $1.27(1.01$ to 1.60$)$ \\
\hline Intrauterine growth retardation & $15 / 503(3.0 \%)$ & $368 / 4946(7.4 \%)$ & 263 & $0.38(0.23$ to 0.65$)$ \\
\hline Fetal distress & $79 / 955(8.3 \%)$ & $309 / 4635(6.7 \%)$ & 122 & $1.27(0.98$ to 1.63$)$ \\
\hline \multicolumn{5}{|l|}{ Antenatal corticosteroids } \\
\hline Partial $<24$ hours & $93 / 1131$ (8.2\%) & $118 / 991$ (11.9\%) & 141 & $0.66(0.50$ to 0.88$)$ \\
\hline Complete and $>7$ days & $180 / 3449(5.2 \%)$ & $118 / 991$ (11.9\%) & & $0.40(0.32$ to 0.52$)$ \\
\hline
\end{tabular}

Table 2 Perinatal risk factors for grades 3-4 IVH in 5712 infants, 1995-97

\begin{tabular}{|c|c|c|}
\hline Perinatal variable & Number (\%) with major IVH & Unadjusted OR $(95 \% \mathrm{CI})$ \\
\hline \multicolumn{3}{|l|}{ Mode of delivery } \\
\hline Vaginal non-breech & $136 / 1819(7.5 \%)$ & 1.0 \\
\hline Vaginal breech & $52 / 454(11.5 \%)$ & 1.60 (1.14 to 2.24$)$ \\
\hline Caesarean section with labour & $96 / 1340(7.2 \%)$ & $0.96(0.73$ to 1.25$)$ \\
\hline Caesarean section without labour & $92 / 1921$ (4.8\%) & $0.62(0.47$ to 0.82$)$ \\
\hline Missing data & 178 & \\
\hline \multicolumn{3}{|l|}{ Birth order } \\
\hline Singleton/first of multiples & $306 / 4219(7.3 \%)$ & 1.0 \\
\hline Second or greater of multiples & $91 / 1493(6.1 \%)$ & $0.83(0.65$ to 1.06$)$ \\
\hline Missing data & 0 & \\
\hline \multicolumn{3}{|l|}{1 minute Apgar score } \\
\hline $4-10$ & $204 / 4371(4.7 \%)$ & 1.0 \\
\hline$<4$ & $185 / 1266(14.6 \%)$ & 3.50 (2.83 to 4.31$)$ \\
\hline Missing data & 75 & \\
\hline \multicolumn{3}{|l|}{ Gender } \\
\hline Female & $159 / 2630(6.0 \%)$ & 1.0 \\
\hline Male & $238 / 3075(7.7 \%)$ & 1.3 (1.06 to 1.60$)$ \\
\hline Missing data & 7 & \\
\hline \multicolumn{3}{|l|}{ Gestational age (weeks) } \\
\hline 30 & $28 / 1368(2.0 \%)$ & 1.0 \\
\hline 29 & $38 / 1159(3.3 \%)$ & 1.62 (0.99 to 2.66$)$ \\
\hline 28 & $53 / 938(5.7 \%)$ & 2.86 (1.80 to 4.56$)$ \\
\hline 27 & $56 / 720(7.8 \%)$ & $4.03(2.54$ to 6.41$)$ \\
\hline 26 & $75 / 690(10.9 \%)$ & 5.83 (3.74 to 9.09$)$ \\
\hline 25 & $78 / 529$ (14.7\%) & 8.27 (5.30 to 12.89$)$ \\
\hline 24 & $69 / 308$ (22.4\%) & 13.80 (8.71 to 21.86$)$ \\
\hline Missing data & 0 & \\
\hline
\end{tabular}

antenatal corticosteroids or gestational age. As both mode of delivery and presentation had strong associations with major IVH on univariate analysis and this association has been described previously in the literature, ${ }^{56}$ further analysis of these variables was undertaken for gestational age strata 24-26 weeks and 27-30 weeks. There was only weak evidence for caesarean section being protective against major IVH in the lower gestational grouping (adjusted OR: 0.80, 95\% CI 0.6 to 1.13). The relation between mode of delivery for breech presentations and major IVH remained non-significant when examined for the same gestational age strata.

Because of this, mode of delivery and presentation were excluded from the final model for major IVH. The variables "fetal distress" and "IUGR" were defined from antenatal variables such as ultrasound results. Because of this, we had concerns about their reliability and reproducibility and decided to exclude them. Therefore, our final model included the five variables: gestation, antenatal corticosteroids, transfer after birth, 1 minute Apgar score < 4, and gender (table 3).

\section{Model validation}

The model was then validated on the 1997 dataset. The areas under the ROC curves were 0.77 (95\% CI 0.73 to 0.82$)$ in the developmental ( 1995 and 1996) and 0.76 (95\% CI 0.73 to 0.79 ) validation datasets (1997), indicating good discriminatory ability. Models containing the same variables were also found to be effective predictors of mortality (ROC $0.79,95 \%$ CI 0.75 to 0.80 ) and IVH grade $2-4$ (ROC $0.75,95 \%$ CI 0.73 to 0.77 ), but less so for any grade of IVH (ROC $0.67,95 \%$ CI 0.66 to 0.69 ) and periventricular leucomalacia (ROC 0.62, 95\% CI 0.57 to 0.66$)$.

\section{DISCUSSION}

This study has shown that while rates of major IVH are falling in Australia and New Zealand, a wide variation in the rate of this outcome exists among individual intensive care nurseries. The goal of this research was to explore the reasons behind this variation. Such variation may be a result of observer bias, in other words there may be differences between centres in the 
Table 3 Final model for 5413 babies with full data on these variables, 1995-97

\begin{tabular}{|c|c|c|c|c|}
\hline \multirow[b]{2}{*}{ Variable } & \multirow{2}{*}{$\begin{array}{l}\text { Logistic regression } \\
\text { coefficient† }\end{array}$} & \multirow{2}{*}{$\begin{array}{l}\text { Severe IVH } \\
\mathrm{n}(\% \text { of } 370)\end{array}$} & \multirow{2}{*}{$\begin{array}{l}\text { No severe IVH } \\
n(\% \text { of } 5043)\end{array}$} & \multirow[b]{2}{*}{ Adjusted OR $(95 \% \mathrm{CI})$} \\
\hline & & & & \\
\hline \multicolumn{5}{|l|}{ Ex utero transfer } \\
\hline No 7 & & $304(82 \%)$ & $4594(91 \%)$ & $1.0 *$ \\
\hline Yes & 0.47 & $66(18 \%)$ & $449(9 \%)$ & $1.60(1.15$ to 2.21$)$ \\
\hline \multicolumn{5}{|l|}{ Antenatal corticosteroids } \\
\hline None & & $103(28 \%)$ & $810(16 \%)$ & $1.0 *$ \\
\hline$<24$ hours & -0.31 & $89(24 \%)$ & $1015(20 \%)$ & $0.73(0.53$ to 1.01$)$ \\
\hline Complete and $>7$ days & -0.67 & $178(48 \%)$ & $3218(64 \%)$ & 0.51 (0.38 to 0.69$)$ \\
\hline \multicolumn{5}{|l|}{1 minute Apgar score } \\
\hline$\geqslant 4$ & & $194(52 \%)$ & $3999(79 \%)$ & $1.0^{*}$ \\
\hline$<4$ & 0.87 & $176(48 \%)$ & $1044(21 \%)$ & 2.39 (1.91 to 3.00$)$ \\
\hline \multicolumn{5}{|l|}{ Gestation in weeks } \\
\hline 30 & & $26(7 \%)$ & $1274(25 \%)$ & $1.0 *$ \\
\hline 29 & 0.51 & $37(10 \%)$ & $1066(21 \%$ & 1.66 (0.99 to 2.76$)$ \\
\hline 28 & 1.02 & 50 (14\%) & $840(17 \%)$ & 2.76 (1.70 to 4.49$)$ \\
\hline 27 & 1.24 & 49 (13\%) & $632(13 \%)$ & 3.45 (2.11 to 5.63$)$ \\
\hline 26 & 1.63 & 69 (19\%) & $583(12 \%)$ & $5.10(3.20$ to 8.15$)$ \\
\hline 25 & 2.09 & $74(20 \%)$ & $423(8 \%)$ & $8.08(5.06$ to 12.90$)$ \\
\hline 24 & 2.41 & $65(18 \%)$ & $225(4 \%)$ & $11.14(6.84$ to 18.16$)$ \\
\hline \multicolumn{5}{|l|}{ Gender } \\
\hline Female & & $149(40 \%)$ & $2352(47 \%)$ & $1.0^{*}$ \\
\hline Male & 0.22 & $221(60 \%)$ & $2691(53 \%)$ & 1.24 (0.99 to 1.55$)$ \\
\hline
\end{tabular}

way ultrasounds are reported. The ANZNN tries to reduce this possibility by using agreed definitions based on the widely used Papile grading. While there are those that argue with some justification that this grading is now outdated, it probably reduces the risk of observer bias simply because it has been so widely used for so long. We did survey all the units to ensure they were using the agreed definitions. Despite this, observer bias cannot be excluded and we are currently performing a study to specifically examine this issue.

Adjusting for confounding variables in different case mixes is the other important step in the process of interhospital outcome comparison. ${ }^{127}$ Established risk adjustment models such as the $\mathrm{CRIB}^{8}$ or SNAP $^{9}$ scores were not appropriate for this study, firstly because not all the necessary variables were collected in the ANZNN dataset, but secondly because both models use postnatal variables which may reflect unit practice variations, exploration of which was the ultimate goal of this research. For this reason, we elected to examine just antenatal and perinatal factors up to and including the 1 minute Apgar score. There is good evidence to suggest that the causal pathway leading to IVH begins in the antenatal, intrapartum, or early postnatal period. ${ }^{4-6}$ The vast majority of IVH occurs within the first 48 hours. IVH present within the first hours of life has been associated with labour and vaginal delivery, suggesting that its origins may well be in utero or intrapartum. ${ }^{4-6}$ Associations between delayed postnatal haemodynamic adaptation and IVH have also been described. ${ }^{6}$ Focusing on the antenatal and intrapartum period also has the advantage of avoiding the problems of multicollinearity and confounding effects encountered when assessing the impact of antenatal corticosteroids and respiratory variables. So ceasing risk adjustment at the time of delivery will facilitate identification of factors in resuscitation and early stabilisation protocols that may be responsible for the differing outcomes among NICUs.

Seven variables retained significance when entered simultaneously into the multivariate regression analysis. Two of these (IUGR and fetal distress) were left out because of concerns about their reproducibility. Gestational age was the most important of the five variables in the final model. Gestational age was selected in preference to birth weight because it reflects fetal maturity more accurately and reasonably accurate assessments of gestation are available for most pregnancies in this region. Birth weight centile was considered for inclusion in the model but, although there was a reduction in grade 3-4 IVH below the tenth centile, this was not statistically significant. The protective role of antenatal corticosteroids is well recognised.$^{10}$ Our analysis confirms their importance, with even partial treatment having a beneficial effect in reduction of grade 3-4 IVH. The high rate of antenatal corticosteroid delivery in our population $(80 \%)$ may explain the much lower rate of major IVH in this study than that reported in an extremely low birth weight population in the USA during the period 1987-91. ${ }^{11}$ The most reliable measure of condition of premature infants at the time of delivery is umbilical arterial $\mathrm{pH}$, but this data is not routinely collected by the ANZNN. Instead we included the 1 minute Apgar score of $<4$, which retained significance in the multivariate regression analysis. A similar observation has been made previously in preterm populations where 1 minute Apgar score $<4$ had a significant association with both neonatal death and cerebral palsy. ${ }^{12}{ }^{13}$ The link between transfer after birth and major IVH has been described in other populations of premature infants ${ }^{14}$ where the referring hospitals routinely transfer all extremely low birth weight infants. This was despite the use of specialist neonatal retrieval services. The adverse association of transfer after birth was greatest for the least mature infants. Finally, we included male gender in our model because it maintained significance as a risk factor, in agreement with other reports. ${ }^{12}{ }^{15}$ There are striking similarities between our findings and those of Synnes et al, who did a very similar analysis in the context of a network of Canadian newborn intensive care units. ${ }^{16}$

Some variables rejected by the multivariate regression process are of interest because they contradict other reports. ${ }^{17}{ }^{18} \mathrm{PIH}$ was not independently protective for major IVH and PROM was not associated with an increased incidence of IVH. However, our definition of PROM was of any rupture more than 24 hours prior to delivery and could not be considered a surrogate for chorioamnionitis. Its apparent protective effect on univariate analysis may be because it identifies cases in which there was sufficient time to allow antenatal 
corticosteroids to be administered or to allow in utero transfer to a level III NICU.

Careful analysis of mode of delivery and major IVH in our survivors beyond day 1 showed weak evidence of a reduced risk when delivery occurred by caesarean section which was most notable in the least mature babies. Although a recent multicentre randomised trial ${ }^{19}$ has shown that planned caesarean section is better than planned vaginal birth for the term breech fetus, we did not find any evidence to suggest that breech presentation posed an additional hazard for the infant of less than 30 weeks gestation. It is also possible that the relation between mode of delivery and IVH is strongest for early $\mathrm{IVH}^{56}$ (that is, IVH apparent shortly after birth). Because timing of IVH is not defined in this dataset, the strength of this association with early IVH may have been diluted by combining it with IVH that occurs later. Interestingly, in the study of Synnes et al, vaginal delivery was a significant risk factor for IVH. ${ }^{16}$ Randomised trials of mode of delivery of the preterm infant are, in practice, extremely difficult and attempts so far have failed to generate adequate power to give meaningful results. ${ }^{20}$ Small observational studies have previously suggested a relation between adverse outcomes of very immature infants and vaginal delivery. ${ }^{45}$ This study provides some evidence that delivery of the very immature infant by caesarean section may reduce morbidity in the survivors.

The predictive properties of our model by area under the ROC curve were 0.77 and 0.76 in the development and validation datasets, respectively, confirming the temporal stability of the model and comparing favourably with the predictive properties of other models based on postnatal scores. ${ }^{21}$ While this model would not be suited to individual case prediction, its use as a risk adjustment tool for large populations before exploring differences in NICUs is justified. The application of this model to examining interhospital outcome differences will be explored in a subsequent paper.

In conclusion, we have confirmed that five antenatal and early perinatal factors alone can predict the rate of grade 3-4 IVH in NICUs with reasonable accuracy. This further supports the theory that many cases of IVH and major IVH in particular have their origins in utero and around the time of delivery. This analysis also confirmed the strong relation between decreasing gestational age and grade 3-4 IVH, the protective role of antenatal corticosteroids, and the need to deliver the very premature infant in specialist centres, avoiding transfer after birth if at all possible, even if specialist retrieval teams are readily available.

\section{ACKNOWLEDGEMENTS}

The authors thank Deborah Donoghue, Dr Rob McClure, and the Directors of NICUs in the ANZNN.

\section{Authors' affiliations}

A M Heuchan, N Evans, Department of Neonatal Medicine, Royal Prince Alfred Hospital and University of Sydney, NSW 2050, Australia D J Henderson Smart, Centre for Perinatal Health Services Research, University of Sydney

J M Simpson, Department of Public Health and Community Medicine, University of Sydney

\section{REFERENCES}

1 Parry JG, Gould CR, McCabe CJ, Tarnow-Mordi WO, on behalf of the International Neonatal Network and the Scottish Neonatal Consultants and Nurses Collaborative Study Group. Annual league tables of mortality in neonatal intensive care units: a longitudinal study. $B M$ 1998;316:1931-5

2 Richardson D, Tarnow-Mordi WO, Lee SK. Risk adjustment for quality improvement. Pediatrics 1999;103(suppl 1):255-65.

3 Papile L-A, Burstein J, Burstein R, Koffler H. Incidence and evolution of subependymal and intraventricular haemorrhage: a study of infants with birth weights less than $1500 \mathrm{gm}$. J Pediatr 1978;92:529-34.

4 Beverley DW, Chance GW, Coates CF. Intraventricular haemorrhage: timing of occurrence and relation to perinatal events. Br J Obstet Gynecol 1984;91:1007-13.

5 Ment LR, Oh W, Philip AGS, Ehrenkranz RA, et al. Risk factors for early intraventricular haemorrhage in low birth weight infants. J Pediatr 1992;121:776-83

6 Kluckow M, Evans N. Low superior vena cava flow and intraventricular haemorrhage in preterm infants. Arch Dis Child Fetal Neonatal Ed 2000;82:F188-94

7 Yates DW, Woodford M, Hollis S. Preliminary analysis of the care of injured patients in 33 British hospitals: first report of the United Kingdom major trauma outcome study. BM 1992;305:737-40.

8 The International Neonatal Network. The CRIB (clinical risk index for babies) score: a tool for assessing initial neonatal risk and comparing performance of neonatal intensive care units. Lancet 1993;342:193-8.

9 Richardson DK, Gray JE, McCormick MC, et al. Score for neonatal acute physiology: a physiologic severity index for neonatal intensive care. Pediatrics 1993;91:617-23.

10 Crowley P. Prophylactic corticosteroids for preterm birth (Cochrane Review). In: The Cochrane Library, Issue 3, Oxford: Update Software, 2001.

11 Shankaran S, Baver CR, Bain R, et al, for the National Institute of Child Health and Human Development Neonatal Research Network. Prenatal and perinatal risk and protective factors for neonatal intracranial haemorrhage. Arch Pediatr Adolesc Med 1996;150:491-7.

12 Beeby PJ, Elliot EJ, Henderson-Smart DJ, Rieger ID. Predictive value of umbilical artery $\mathrm{pH}$ in preterm infants. Arch Dis Child Fetal Neonatal Ed 1994;71:F93-6.

13 Gaudier FL, Goldenberg RL, Nelson KG, et al. Influence of acid-base status at birth and Apgar scores on survival in 500-1000-g infants. Obstet Gynecol 1996;87:175-80

14 Clark CE, Clyman RI, Rosth RS, et al. Risk factor analysis of intraventricular hemorrhage in low-birth-weight infants. J Pediatr 1981;99:625-8.

15 Szymonowicz W, Yu VYH, Wilson FE. Antecedents of periventricular haemorrhage in infants weighing $1250 \mathrm{~g}$ or less at birth. Arch Dis Child 1984;59:13-17.

16 Synnes A, Peliowski A, Baboola R, et al. Risk factors for intraventricular haemorrhage rates in Neonatal Intensive Care Unit patients. J Pediatr $2001 ; 138: 525-31$.

17 Perlman JM, Risser RC, Gee JB. Pregnancy-induced hypertension and reduced inraventricular hemorrhage in preterm infants. Pediatr Neurol 1997; 17:29-33.

18 Verma U, Tejani N, Klein S, et al. Obstetric antecedents of intraventricular leukomalacia in the low-birth-weight neonate. Am J Obstet Gynecol 1997; 176:275-81.

19 Hanah MA, Hannah W J, Hewson SA, et al, for the Term Breech Trial Collabarative Group. Planned caesarean section versus planned vaginal birth for breech presentation at term: a randomised multicentre trial. Lancet 2000;356:1375-83.

20 Grant A, Glazener CMA. Elective caesarean section versus expectant management for delivery of the small baby (Cochrane Review). In: The Cochrane Library, Issue 3, Oxford: Update Software, 2001.

21 Pollack MM, Koch MA, Bartel DA, et al. A comparison of neonatal mortality risk prediction models in very low birth weight infants. Pediatrics 2000; 105:1051-7. 